\title{
Prevalence and Incidence of Atrial Fibrillation in the General Population Based on National Health Insurance Special Health Checkups - TAMA MED Project-AF -
}

\author{
Eitaro Kodani, MD, PhD; Tomohiro Kaneko, MD, PhD; Hitomi Fujii, MD, PhD; \\ Hiroyuki Nakamura, MD, PhD; Hajime Sasabe, MD, PhD; \\ Yutaka Tamura, MD, PhD; Wataru Shimizu, MD, PhD
}

\begin{abstract}
Background: Although National Health Insurance special health checkups have been useful for the diagnosis of metabolic syndrome, they are insufficient to identify atrial fibrillation (AF). In Tama City in Tokyo, 12-lead electrocardiogram has been included as an essential examination in special health checkups to diagnose AF since 2008.
\end{abstract}

\begin{abstract}
Methods and Results: In subjects aged 40-74 years at entry, prevalence of AF was $0.8 \%$ (men, 1.7\%; women, $0.2 \%$ ) in 2008 and $1.4 \%$ (men, 2.9\%; women, $0.4 \%$ ) in 2015. Of 10,430 subjects without AF in 2008 (mean age, $64.9 \pm 7.1$ years; men, 40.4\%), AF developed in 133 between 2008 and 2015. The incidence rate of new-onset AF was 2.5/1,000 person-years during an observation period of 52,707 person-years. On multivariate Cox regression analysis in subjects without a history of cardiac disease, hypertension (HR, 1.58; 95\% Cl: 1.01-2.47, $\mathrm{P}=0.045$ ) and body mass index (BMl; /1-kg/ $\mathrm{m}^{2}$ increase; $\mathrm{HR}, 1.07 ; 95 \% \mathrm{Cl}: 1.00-1.12, \mathrm{P}=0.049$ ) were significant risk factors for new-onset $A F$ in addition to age and male sex.
\end{abstract}

Conclusions: Prevalence of AF increased between 2008 and 2015. Age, male sex, hypertension, and BMI were significant predictors for future incidence of $\mathrm{AF}$ in the general population without overt cardiac disease. Controlling hypertension and BMI may prevent new-onset $\mathrm{AF}$ in the general population.

Key Words: Atrial fibrillation; General population; Health checkup; Incidence; Prevalence

A trial fibrillation (AF) is a common arrhythmia and a strong risk factor for cardiogenic thromboembolism., ${ }^{\mathbf{1} 2}$ In order to reduce the incidence of cardiogenic stroke, both prevention of new-onset AF and early detection of undiagnosed AF prior to the initiation of appropriate anticoagulation therapy are important ${ }^{3}$ in the general healthy population. In Japan, special health checkups, so-called "Tokutei kenshin", were introduced in 2008 to identify lifestyle-related diseases intended for individuals who have national health insurance. Although the special health checkups are useful for the diagnosis of metabolic syndrome, ${ }^{4}$ they are insufficient to diagnose AF because the recording of electrocardiograms (ECG) is not mandatory. Therefore, in Tama City in the suburbs of Tokyo, 12-lead ECG has been included as an essential examination in special health checkups to diagnose AF since 2008. Using the ECG findings of the special health checkups, the aim of this study was to clarify the prevalence and incidence of AF in apparently healthy individuals in the general population and identify the risk factors for new-onset AF in subjects who did not have AF in 2008.

\section{TAMA MED Project-AF}

\section{Methods}

The TAMA MED Project-AF was conducted as a retrospective cohort study to clarify the prevalence and incidence of AF in the general population. The study protocol conformed to the Declaration of Helsinki and was approved by the institution ethics committee. A consecutive series of subjects who had national health insurance and underwent annual special health checkups at a clinic or hospital belonging to the TAMA CITY Medical Association were recruited. All participants were aged 40-74 years at the

Received September 12, 2018; revised manuscript received November 18, 2018; accepted November 26, 2018; J-STAGE Advance Publication released online January 11, 2019 Time for primary review: 34 days

Department of Internal Medicine and Cardiology (E.K.), Department of Nephrology (T.K.), Nippon Medical School Tama-Nagayama Hospital, Tokyo; Tama-center Mirai Clinic, Tokyo (H.F.); TAMA CITY Medical Association, Tokyo (E.K., H.F., H.N., H.S., Y.T.); and Department of Cardiovascular Medicine, Nippon Medical School, Tokyo (W.S.), Japan

Mailing address: Eitaro Kodani, MD, PhD, Department of Internal Medicine and Cardiology, Nippon Medical School Tama-Nagayama Hospital, 1-7-1 Nagayama, Tama, Tokyo 206-8512, Japan. E-mail: kodani@nms.ac.jp

ISSN-1346-9843 All rights are reserved to the Japanese Circulation Society. For permissions, please e-mail: cj@j-circ.or.jp 


\begin{tabular}{|c|c|c|c|}
\hline & 2008 & 2015 & P-value* \\
\hline No. subjects & 12,137 & 12,303 & \\
\hline Age (years) & $65.2 \pm 7.6$ & $67.0 \pm 7.3$ & $<0.001$ \\
\hline Sex, men & $5,050(41.6)$ & $5,034(40.9)$ & 0.272 \\
\hline $\mathrm{BMI}\left(\mathrm{kg} / \mathrm{m}^{2}\right)$ & $22.6 \pm 3.2$ & $22.6 \pm 3.3$ & 0.121 \\
\hline $\mathrm{SBP}(\mathrm{mmHg})$ & $128.7 \pm 16.5$ & $127.2 \pm 16.5$ & $<0.001$ \\
\hline $\mathrm{DBP}(\mathrm{mmHg})$ & $76.2 \pm 10.4$ & $74.5 \pm 10.4$ & $<0.001$ \\
\hline Current smoker & $2,772(22.8)$ & 2,697 (22.2) & 0.082 \\
\hline Past history & $8,011(66.0)$ & $8,747(72.1)$ & $<0.001$ \\
\hline Present illness & $2,679(22.1)$ & $2,525(20.8)$ & 0.003 \\
\hline \multicolumn{4}{|l|}{ Comorbidities } \\
\hline Cardiac disease $^{\dagger}$ & $578(4.8)$ & $749(6.1)$ & $<0.001$ \\
\hline Hypertension & $4,928(40.6)$ & $5,235(42.6)$ & 0.002 \\
\hline DM & $1,441(11.9)$ & 1,603 (13.0) & 0.006 \\
\hline Stroke/TIA & $412(3.4)$ & $488(4.0)$ & 0.096 \\
\hline Metabolic syndrome & $1,659(13.7)$ & $1,837(14.9)$ & 0.007 \\
\hline \multicolumn{4}{|l|}{ Blood examinations } \\
\hline HDL-C (mg/dL) & $63.7 \pm 16.7$ & $64.5 \pm 16.6$ & $<0.001$ \\
\hline LDL-C (mg/dL) & $126.7 \pm 30.1$ & $124.6 \pm 30.4$ & $<0.001$ \\
\hline Triglycerides (mg/dL) & $115.8 \pm 78.8$ & $114.4 \pm 80.1$ & 0.176 \\
\hline HbA1c (NGSP) (\%) & $5.6 \pm 0.7^{\ddagger}$ & $5.7 \pm 0.6$ & $<0.001$ \\
\hline AST (IU/L) & $24.8 \pm 11.1$ & $24.5 \pm 11.7$ & 0.052 \\
\hline ALT (IU/L) & $21.9 \pm 14.0$ & $21.2 \pm 14.2$ & 0.001 \\
\hline$\gamma$-GTP (IU/L) & $37.4 \pm 48.6$ & $35.2 \pm 50.2$ & $<0.001$ \\
\hline \multicolumn{4}{|l|}{ Urinalysis } \\
\hline Urine sugar & $279(2.3)$ & $280(2.3)$ & 0.876 \\
\hline Urine protein & $646(5.3)$ & $517(4.2)$ & $<0.001$ \\
\hline \multicolumn{4}{|l|}{ Medication } \\
\hline For hypertension & $3,602(29.7)$ & $4,206(34.2)$ & $<0.001$ \\
\hline For diabetes mellitus & $743(6.1)$ & $1,011(8.2)$ & $<0.001$ \\
\hline For dyslipidemia & $1,924(15.9)$ & $2,693(21.9)$ & $<0.001$ \\
\hline
\end{tabular}

Data given as $\mathrm{n}(\%)$ or mean \pm SD. ${ }^{\dagger}$ Self-reported. ${ }^{*} \mathrm{HbA} 1 \mathrm{c}(\mathrm{JDS})+0.4 \%$. ${ }^{*}$ Comparison between 2008 and 2015. $\gamma$-GTP, $\gamma$-glutamyl transpeptidase; ALT, alanine transaminase; AST, aspartate transaminase; BMI, body mass index; DBP, diastolic blood pressure; DM, diabetes mellitus; HbA1c, glycated hemoglobin; HDL-C, high-density lipoprotein cholesterol; JDS, Japan Diabetes Society; LDL-C, low-density lipoprotein cholesterol; NGSP, National Glycohemoglobin Standardization Program; SBP, systolic blood pressure; TIA, transient ischemic attack.

time of entry because the special health checkups are open for subjects aged $\geq 40$ years, and individuals aged $\geq 75$ years are not eligible for this insurance. Age at the end of the fiscal year was recorded in the Tama City database and was used for subsequent analyses. All participants completed the questionnaire, which included items to evaluate self-reported past history, such as cardiac disease, stroke, gastrointestinal disease, renal disease, malignancy, and so on; present illness (the presence of any subjective symptom at the time of special health checkups, including noncardiac symptoms); habitual status, including current smoking; and medication use. The following measurements were obtained for all participants: body height and weight, body mass index (BMI), waist circumference, and systolic and diastolic blood pressure (SBP and DBP). According to an ordinance of the Ministry of Health, Labour and Welfare referred to as Article 157 in 2007, the following essentials were examined: fasting plasma glucose (FPG) or glycated hemoglobin (HbA1c), serum high-density lipoprotein cholesterol (HDL-C), serum low-density lipoprotein cholesterol (LDL-C), triglycerides, aspartate transaminase, alanine transaminase, $\gamma$-glutamyl transpep- tidase $(\gamma$-GTP), and urine sugar and protein. Hypertension was defined as $\mathrm{SBP} \geq 140 \mathrm{mmHg}, \mathrm{DBP} \geq 90 \mathrm{mmHg}$, and/or receiving antihypertensive medication. Diabetes mellitus was defined as FPG $\geq 126 \mathrm{mg} / \mathrm{dL}, \mathrm{HbA} 1 \mathrm{c} \geq 6.1 \%$ (Japan Diabetes Society) or $\geq 6.5 \%$ (National Glycohemoglobin Standardization Program), and/or receiving medical treatment containing oral hypoglycemic agents and/or insulin. In addition, a standard 12-lead ECG was recorded for all participants as a Tama City-specific mandatory optional examination. AF was diagnosed directly by physicians or based on automatic analysis of 12-lead ECG in each clinic or hospital, regardless of the electrocardiograph model and vendor. All annual health checkups in 2015 were used to clarify the most recent prevalence of AF. To calculate the incidence rate of new-onset AF, individuals who did not have AF in 2008 were enrolled for this analysis.

\section{Statistical Analysis}

Data are presented as mean \pm SD. The significance of differences in means was analyzed using Student's t-test. Frequencies of parameters were compared using the chisquared test. Kaplan-Meier curves were generated to show 


\begin{tabular}{|c|c|c|c|c|c|c|c|c|c|}
\hline \multirow{2}{*}{$\begin{array}{l}\text { Age (years) } \\
\text { (at the end } \\
\text { of the year) }\end{array}$} & \multicolumn{3}{|c|}{ Men } & \multicolumn{3}{|c|}{ Women } & \multicolumn{3}{|c|}{ Overall } \\
\hline & $\begin{array}{c}\text { No. } \\
\text { subjects }\end{array}$ & $\begin{array}{c}\text { No. } \\
\text { with AF }\end{array}$ & $\begin{array}{l}\text { Prevalence } \\
\text { of AF (\%) }\end{array}$ & $\begin{array}{c}\text { No. } \\
\text { subjects }\end{array}$ & $\begin{array}{c}\text { No. } \\
\text { with AF }\end{array}$ & $\begin{array}{c}\text { Prevalence } \\
\text { of AF (\%) }\end{array}$ & $\begin{array}{c}\text { No. } \\
\text { subjects }\end{array}$ & $\begin{array}{c}\text { No. } \\
\text { with AF }\end{array}$ & $\begin{array}{c}\text { Prevalence } \\
\text { of AF (\%) }\end{array}$ \\
\hline \multicolumn{10}{|l|}{2008} \\
\hline $40-44$ & 173 & 0 & 0 & 195 & 0 & 0 & 368 & 0 & 0.0 \\
\hline $45-49$ & 173 & 0 & 0 & 190 & 0 & 0 & 363 & 0 & 0.0 \\
\hline $50-54$ & 167 & 1 & 0.6 & 272 & 0 & 0 & 439 & 1 & 0.2 \\
\hline $55-59$ & 305 & 1 & 0.3 & 623 & 1 & 0.2 & 928 & 2 & 0.2 \\
\hline $60-64$ & 745 & 13 & 1.7 & 1,492 & 1 & 0.1 & 2,237 & 14 & 0.6 \\
\hline $65-69$ & 1,653 & 33 & 2.0 & 2,217 & 4 & 0.2 & 3,870 & 37 & 1.0 \\
\hline $70-74$ & 1,661 & 30 & 1.8 & 1,927 & 10 & 0.5 & 3,588 & 40 & 1.1 \\
\hline 75 & 173 & 7 & 4.0 & 171 & 0 & 0.0 & 344 & 7 & 2.0 \\
\hline Total & 5,050 & 85 & 1.7 & 7,087 & 16 & 0.2 & 12,137 & 101 & 0.8 \\
\hline \multicolumn{10}{|l|}{2015} \\
\hline $40-44$ & 104 & 0 & 0 & 132 & 0 & 0 & 236 & 0 & 0 \\
\hline $45-49$ & 206 & 0 & 0 & 204 & 0 & 0 & 410 & 0 & 0 \\
\hline $50-54$ & 188 & 0 & 0 & 220 & 0 & 0 & 408 & 0 & 0 \\
\hline $55-59$ & 207 & 1 & 0.5 & 325 & 0 & 0 & 532 & 1 & 0.2 \\
\hline $60-64$ & 391 & 4 & 1.0 & 919 & 1 & 0.1 & 1,310 & 5 & 0.4 \\
\hline $65-69$ & 1,628 & 44 & 2.7 & 2,443 & 9 & 0.4 & 4,071 & 53 & 1.3 \\
\hline $70-74$ & 2,009 & 78 & 3.9 & 2,668 & 17 & 0.6 & 4,677 & 95 & 2.0 \\
\hline 75 & 301 & 17 & 5.6 & 358 & 4 & 1.1 & 659 & 21 & 3.2 \\
\hline Total & 5,034 & 144 & 2.9 & 7,269 & 31 & 0.4 & 12,303 & 175 & 1.4 \\
\hline
\end{tabular}

$\mathrm{AF}$, atrial fibrillation.

the cumulative incidence of AF from 2008 to 2015, and the time to events was compared between sex, age, BP, and BMI classes on log-rank test. A Cox proportional hazard model was used to investigate the influence of clinical factors on new-onset AF. Hazard ratios (HR) and 95\% confidence intervals (CI) for the presence of categorical variables and for each 1-unit increase of continuous variables were calculated. Explanatory variables for multivariate analysis were adopted for significant variables in univariate analysis except for SBP, DBP, and medication for hypertension, to avoid multicollinearity with hypertension. HbAlc and medication for diabetes mellitus were also not included to avoid multicollinearity with diabetes mellitus. In addition, to detect significant risk factors except cardiac disease, multivariate analysis was conducted after exclusion of subjects with a history of cardiac disease. The prediction ability of risk factors was determined using area under the receiver operating characteristic (ROC) curve (AUC), and the optimal cut-offs for new-onset AF were determined as the values at maximum Youden index (=sensitivity+specificity -1$)$ on the ROC curves. Two-tailed $\mathrm{P}<0.05$ was considered statistically significant. All statistical analysis was performed using SPSS version 23.0 (IBM, Armonk, NY, USA).

\section{Results}

\section{Prevalence of AF}

Of 12,149 participants in 2008,12 were excluded due to a deficit of system data. Characteristics for all subjects in 2008 and 2015 are shown in Table 1. The prevalence of hypertension, diabetes, metabolic syndrome, and medication for comorbidities was higher in 2015 than in 2008. The number of cases of AF and prevalence of AF in 12,137 participants at the time of initiation of the special health checkups in 2008 and those most recently in 12,303 participants in 2015 are shown in Table 2, Figure 1. The overall prevalence rate of AF was $0.8 \%$ (men, $1.7 \%$; women, $0.2 \%$ ) in 2008 (Table 2) and 1.4\% (men, 2.9\%; women, $0.4 \%$ ) in 2015 (Table 2). The prevalence of AF was higher in men than in women, and increased from 2008 to 2015, especially in men. In 2015, an increasing trend in the prevalence of AF with age class was clearly observed in both men and women (Figure 1). When age was divided into 10-year classes, the prevalence of AF in age classes 50-59, 60-69, and $70-79$ years was $0.3 \%, 2.4 \%$, and $4.1 \%$ in men and $0 \%, 0.3 \%$, and $0.7 \%$ in women, respectively, in 2015 (Supplementary Figure 1).

\section{Subjects Without AF in 2008: Baseline Characteristics}

Of 12,137 participants, 101 who had AF at the time of entry and 1,606 who underwent special health checkups only once in 2008 were excluded. Consequently, a total of 10,430 subjects who did not have AF in 2008 and underwent annual checkups at least once between 2009 and 2015 were enrolled to calculate the incidence rate of new-onset AF. Baseline characteristics of subjects without AF in 2008 $(n=10,430)$ are listed in Supplementary Table 1. Characteristics are also shown separately for participants who subsequently developed AF (onset-AF, $n=133$ ) and who did not (no-AF, n=10,297) until 2015. Age, BMI, SBP and DBP, $\gamma$-GTP; and the frequency of current smokers, any past history, cardiac disease, hypertension, diabetes mellitus, and metabolic syndrome in the onset-AF group were significantly higher than in the no-AF group, whereas LDL-C in the onset-AF group was significantly lower than in the no-AF group (Supplementary Table 1). Consequently, the frequency of receiving medical treatment for hypertension and diabetes mellitus in the onset-AF group were significantly higher than in the no-AF group (Supplementary 


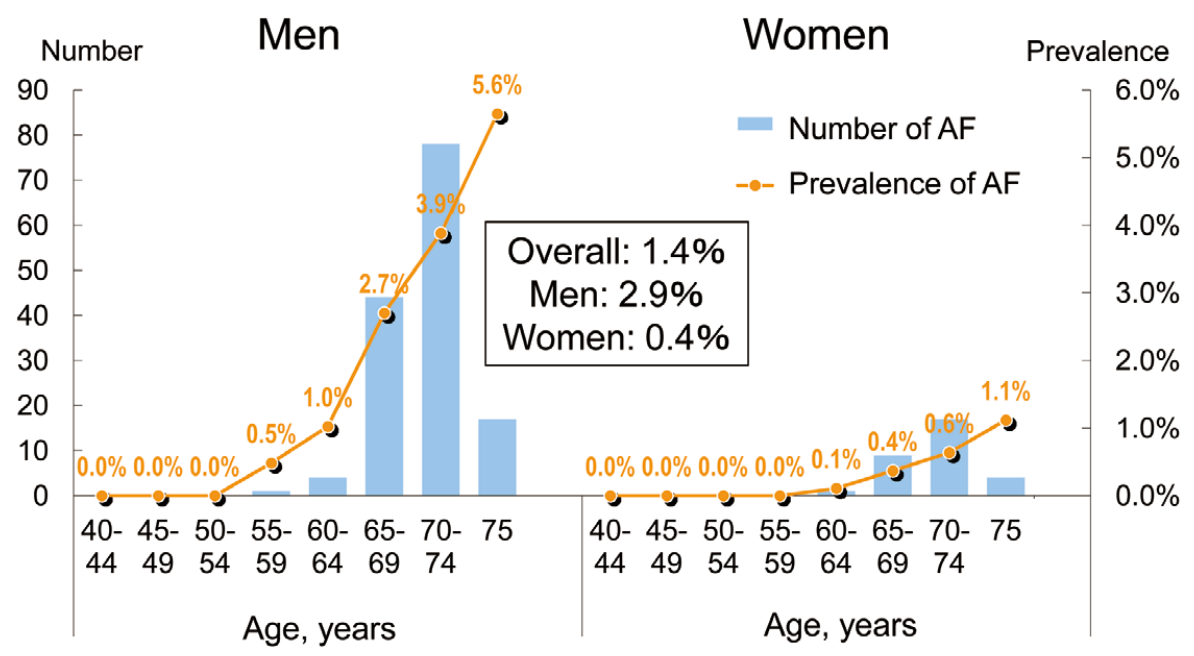

Figure 1. No. cases and prevalence of atrial fibrillation (AF) in Tama City in 2015. The subjects consisted of 12,303 individuals (5,034 men and 7,269 women) who underwent annual special health checkups in the TAMA CITY Medical Association in 2015. Age is given at year end.

Table 1). After exclusion of subjects with a history of cardiac disease, baseline characteristics of subjects without AF in $2008(n=9,992)$ are shown in Supplementary Table 2.

\section{Incidence of New-Onset AF}

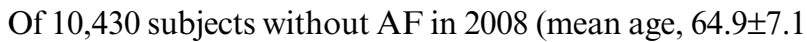
years; men, 40.4\%), AF developed in $133(1.3 \%)$ between 2008 and 2015. The overall incidence rate of new-onset AF was 2.5/1,000 person-years during an observation period of 6.9 years (52,707 person-years; Figure 2). It was $4.5 / 1,000$ person-years $(20,468$ person-years) in men and $1.3 / 1,000$ person-years $(32,239$ person-years $)$ in women, respectively. The cumulative rate of new-onset AF in men was significantly higher than that in women $(\mathrm{P}<0.001, \log -$ rank test; Figure 3A). There was a significant difference in the rate of new-onset AF by age class $(\mathrm{P}<0.001$, log-rank test; Figure 3B). After exclusion of 438 subjects with a history of cardiac disease $(n=9,992)$, AF developed in 105 (1.1\%) until 2015 and the incidence rate of new-onset AF was 2.1/1,000 person-years during an observation period of 7.0 years $(50,810$ person-years $)$. The number of subjects who underwent the special health checkups completely every year was 4,723 (45.3\% of all). Of these subjects, AF developed in $67(1.4 \%)$ until 2015 and the incidence rate of newonset $\mathrm{AF}$ was 2.0/1,000 person-years during an observation period of 7.0 years $(32,869$ person-years). It was not different from that in 10,430 subjects $(\mathrm{P}=0.146, \log$-rank test $)$.

\section{Predictors for New-Onset AF}

On univariate analysis, age, male sex, BMI, a history of cardiac disease, hypertension, diabetes mellitus, SBP, DBP, $\mathrm{HbA1c}$, triglycerides, and $\gamma$-GTP were positively correlated with new-onset AF; meanwhile, LDL-C, current smoking, and receiving medication for hypertension and diabetes mellitus were negatively correlated with new-onset AF (Table 3). On multivariate analysis, only age (/1-year increase; HR, 1.07; 95\% CI: 1.03-1.12, P=0.001), male sex (HR, 2.76; 95\% CI: $1.67-4.57, \mathrm{P}<0.001)$, and a history of cardiac disease (HR, 4.47; 95\% CI: 2.73-7.32, $\mathrm{P}<0.001)$ were

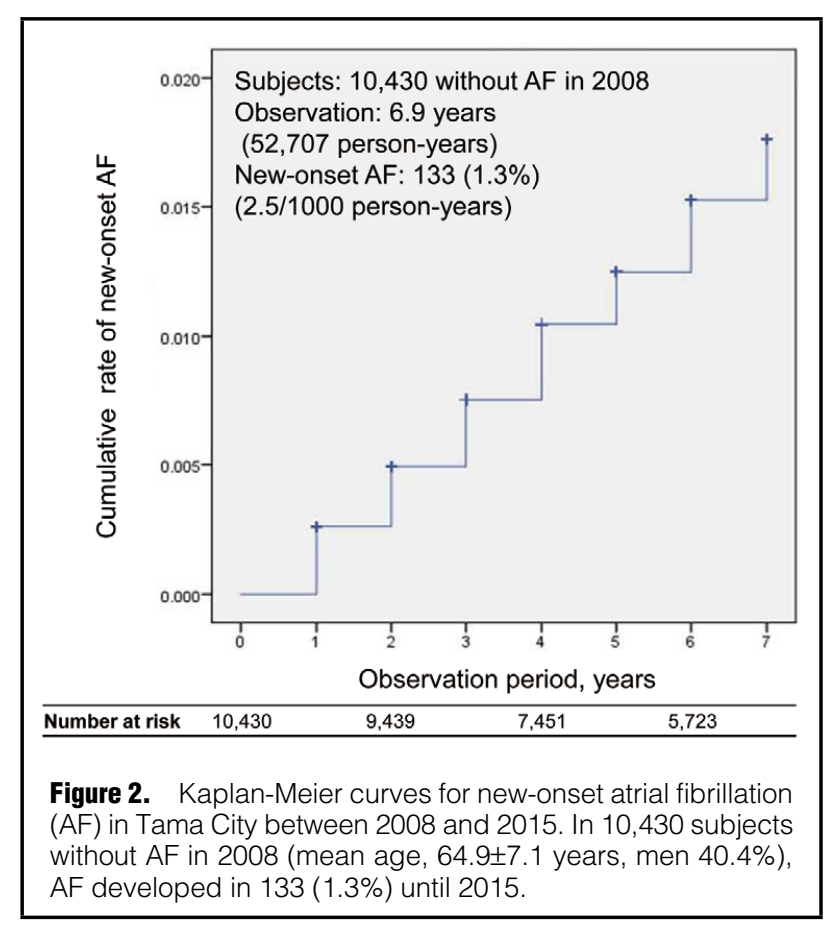

significant risk factors for new-onset AF (Table 3). Given that a history of cardiac disease, as obtained from the self-reported questionnaire in the special health checkups, contains various unknown cardiac diseases, further analysis was performed to clarify the predictors for new-onset AF in subjects without an obvious history of cardiac disease. In 9,992 subjects without a history of cardiac disease, hypertension (HR, 1.58; 95\% $\%$ I: $1.01-2.47, \mathrm{P}=0.045)$ and $\mathrm{BMI}$ (/1-kg/m² increase, HR, 1.07; 95\% CI: $1.00-1.12, \mathrm{P}=0.049)$ were significant risk factors for new-onset $\mathrm{AF}$ in addition to age and male sex (Table 4). 

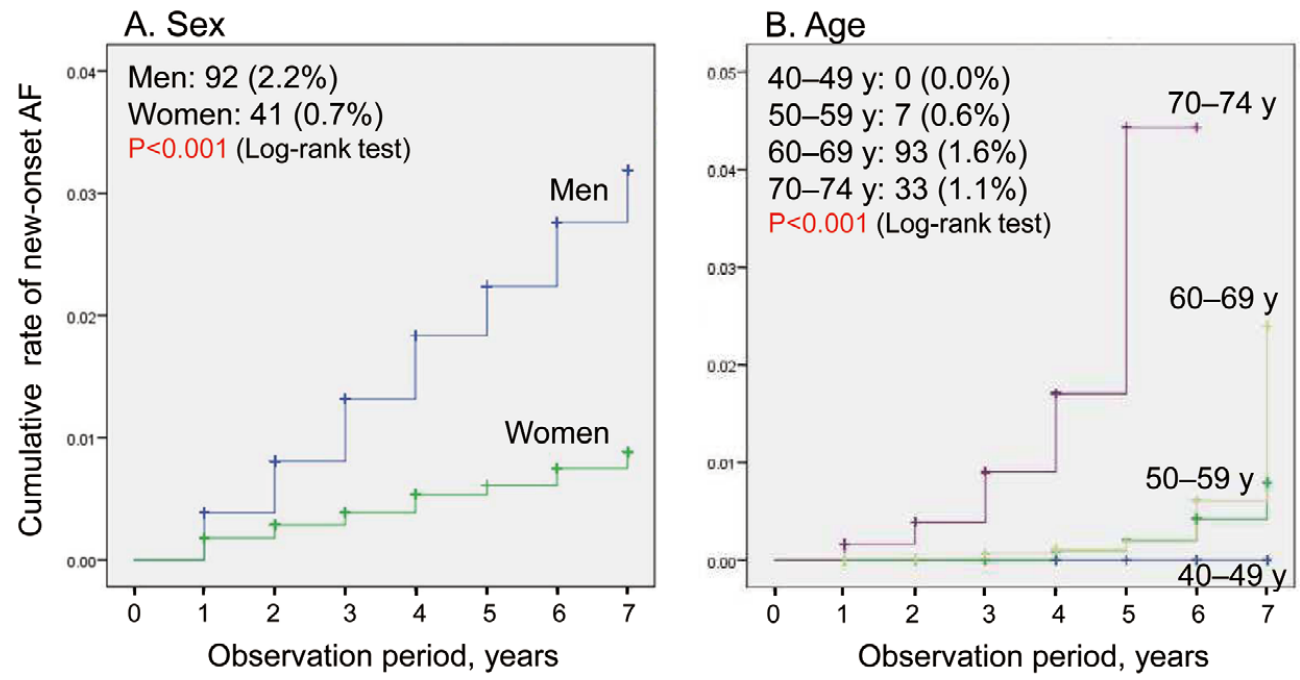

Figure 3. Kaplan-Meier curves for new-onset atrial fibrillation (AF) in Tama City between 2008 and 2015 according to (A) sex and (B) age.

Table 3. Significant Indicators of New-Onset AF (Cox Proportional Hazard Model, $n=10,430$ )

\begin{tabular}{|c|c|c|c|c|}
\hline \multirow{2}{*}{ Variables } & \multicolumn{2}{|c|}{ Univariate $^{\dagger}$} & \multicolumn{2}{|c|}{ Multivariate ${ }^{\ddagger}$} \\
\hline & $\mathrm{HR}(95 \% \mathrm{Cl})$ & P-value & $\mathrm{HR}(95 \% \mathrm{Cl})$ & P-value \\
\hline Cardiac disease & $7.146(4.707-10.849)$ & $<0.001$ & $4.467(2.727-7.319)$ & $<0.001$ \\
\hline Hypertension & $2.144(1.520-3.023)$ & $<0.001$ & $1.435(0.960-2.145)$ & 0.078 \\
\hline DM & $1.845(1.156-2.871)$ & 0.007 & $1.143(0.686-1.905)$ & 0.608 \\
\hline Age (/1-year increase) & $1.100(1.058-1.144)$ & $<0.001$ & $1.071(1.027-1.117)$ & 0.001 \\
\hline Sex (men) & $3.546(2.451-5.128)$ & $<0.001$ & $2.755(1.667-4.566)$ & $<0.001$ \\
\hline BMI (/1-kg/m² increase) & $1.072(1.037-1.109)$ & $<0.001$ & $1.046(0.983-1.114)$ & 0.154 \\
\hline SBP (/1-mmHg increase) & $1.024(1.015-1.033)$ & $<0.001$ & - & \\
\hline DBP (/1-mmHg increase) & $1.035(1.019-1.051)$ & $<0.001$ & - & \\
\hline $\mathrm{HbA} 1 \mathrm{c}(/ 1 \%$ increase $)$ & $1.254(1.030-1.528)$ & 0.024 & - & \\
\hline LDL-C (/1-mg/dL increase) & $0.988(0.982-0.993)$ & $<0.001$ & $0.995(0.988-1.002)$ & 0.131 \\
\hline Triglycerides (/1-mg/dL increase) & $1.002(1.000-1.003)$ & 0.006 & $1.001(0.999-1.002)$ & 0.292 \\
\hline$\gamma$-GTP (/1-IU/L increase) & $1.004(1.002-1.005)$ & $<0.001$ & $1.002(1.000-1.005)$ & 0.092 \\
\hline Current smoking & $0.680(0.468-0.988)$ & 0.043 & $1.051(0.669-1.651)$ & 0.829 \\
\hline Medication for hypertension & $0.450(0.320-0.634)$ & $<0.001$ & - & \\
\hline Medication for DM & $0.453(0.265-0.775)$ & 0.004 & - & \\
\hline
\end{tabular}

${ }^{\dagger}$ Non-significant variables in univariate analysis are not shown. ${ }^{\mathrm{SBBP}}$ and DBP, $\mathrm{HbA1c}$, and medications for hypertension and DM were not included in multivariate analysis to avoid multicollinearity. Abbreviations as in Table 1.

\section{Influence of Hypertension, BP, and BMI on New-Onset AF}

Given that hypertension and BMI were associated with an increase in the risk of new-onset AF in the multivariate Cox hazard model, additional Kaplan-Meier curves were generated to show the cumulative incidence of $\mathrm{AF}$ based on the presence of hypertension (Figure 4A), BMI class (Figure 4B), and the quartiles of SBP and DBP (Supplementary Figure 2). There were significant differences in the incidence of AF between the presence of hypertension, BMI classes, and BP quartiles based on logrank test (Figure 4, Supplementary Figure 2). The prediction ability (AUC) of SBP and BMI for new-onset AF was 0.610 (95\% CI: $0.562-0.658, \mathrm{P}<0.001)$ and 0.583 (95\% CI: $0.533-0.633, \mathrm{P}=0.001)$, respectively. The cut-offs of SBP and BMI, for which interventions are possible, were $129.5 \mathrm{mmHg}$ (sensitivity, 66.9\%; specificity, 51.6\%) and $22.5 \mathrm{~kg} / \mathrm{m}^{2}$ (sensitivity, $63.2 \%$; specificity, $51.7 \%$ ), respectively.

\section{Discussion}

The major findings of the present study were as follows. First, the prevalence of AF increased between 2008 and 2015; and was $1.4 \%$ (men, $2.9 \%$; women, $0.4 \%$ ) in subjects aged 40-74 years at entry in the general population in 2015. Second, the incidence rate of new-onset AF was $2.5 / 1,000$ person-years $(4.5 / 1,000$ person-years in men and $1.3 / 1,000$ person-years in women). Third, age, male sex, 
Table 4. Significant Indicators of New-Onset AF After Exclusion of Subjects With a History of Cardiac Disease (Cox Proportional Hazard Model, $n=9,992)$

\begin{tabular}{|c|c|c|c|c|}
\hline \multirow{2}{*}{ Variables } & \multicolumn{2}{|c|}{ Univariate $^{\dagger}$} & \multicolumn{2}{|c|}{ Multivariate $^{\ddagger}$} \\
\hline & HR $(95 \% \mathrm{Cl})$ & P-value & $\mathrm{HR}(95 \% \mathrm{Cl})$ & P-value \\
\hline Cardiac disease (excluded) & - & & - & \\
\hline Hypertension & $2.288(1.552-3.372)$ & $<0.001$ & $1.582(1.011-2.474)$ & 0.045 \\
\hline DM & $1.900(1.156-3.123)$ & 0.011 & $1.263(0.721-2.213)$ & 0.414 \\
\hline Age (/1-year increase) & $1.108(1.059-1.159)$ & $<0.001$ & $1.093(1.041-1.148)$ & $<0.001$ \\
\hline Sex (men) & $3.534(2.342-5.348)$ & $<0.001$ & $2.632(1.513-4.587)$ & $<0.001$ \\
\hline BMI (/1-kg/m² increase) & $1.078(1.041-1.116)$ & $<0.001$ & $1.072(1.000-1.120)$ & 0.049 \\
\hline SBP (/1-mmHg increase) & $1.026(1.016-1.036)$ & $<0.001$ & - & \\
\hline DBP (/1-mmHg increase) & $1.037(1.019-1.055)$ & $<0.001$ & - & \\
\hline $\mathrm{HbA} 1 \mathrm{c}(/ 1 \%$ increase $)$ & $1.269(1.023-1.575)$ & 0.030 & - & \\
\hline LDL-C (/1-mg/dL increase) & $0.990(0.983-0.996)$ & 0.003 & $0.887(0.594-1.322)$ & 0.555 \\
\hline Triglycerides (/1-mg/dL increase) & $1.002(1.001-1.003)$ & 0.004 & $1.001(0.999-1.002)$ & 0.203 \\
\hline Y-GTP (/1-IU/L increase) & $1.003(1.001-1.005)$ & 0.002 & $1.001(0.998-1.005)$ & 0.348 \\
\hline Medication for hypertension & $0.489(0.331-0.720)$ & $<0.001$ & - & \\
\hline Medication for DM & $0.396(0.221-0.707)$ & 0.002 & - & \\
\hline
\end{tabular}

tNon-significant variables in univariate analysis are not shown. ${ }^{\text {SSBP }}$ and DBP, HbA1c, and medication for hypertension and DM were not included in multivariate analysis to avoid multicollinearity. Abbreviations as in Table 1.
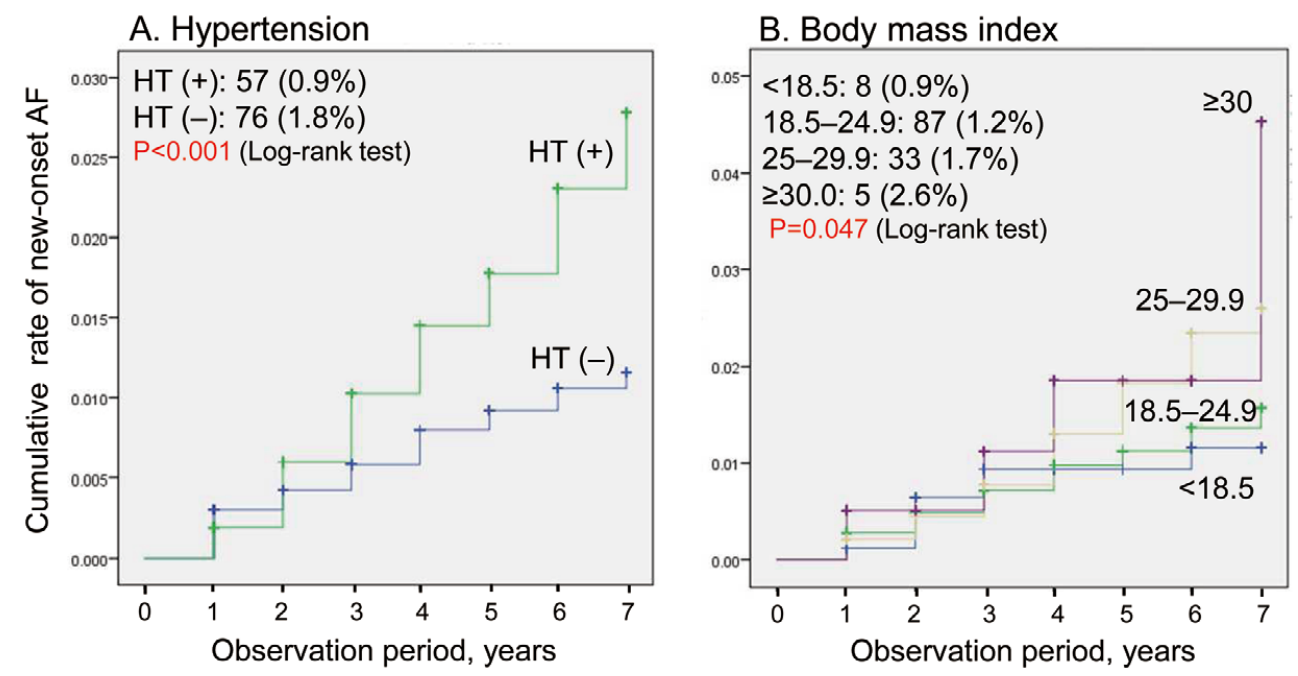

Figure 4. Kaplan-Meier curves for new-onset atrial fibrillation (AF) in Tama City between 2008 and 2015 according to (A) presence of hypertension (HT) and $(\mathbf{B})$ body mass index class $\left(\mathrm{kg} / \mathrm{m}^{2}\right)$.

hypertension, and BMI were significant predictors for the future incidence of AF in the general population without overt cardiac disease.

\section{Prevalence of AF}

The prevalence of AF has been investigated in several previous studies in Western countries ${ }^{2,5-7}$ and in Japan. ${ }^{8-10}$ In the USA in 1991, the overall prevalence of AF was $0.89 \%$; was $2.3 \%$ in adults aged $>40$ years; and was $5.9 \%$ in those aged $>65$ years, indicating that AF prevalence increased with age. ${ }^{2}$ In England and Wales, the prevalence of AF in 1998 was $1.21 \%$ in men and $1.27 \%$ in women. ${ }^{5}$ In a recent systematic review of 184 population-based studies of AF from 1980 to $2010,{ }^{7}$ the prevalence of $\mathrm{AF}$ in 2010 was
$0.60 \%$ in men and $0.37 \%$ in women. It increased from 1990 and was consistently higher in men than in women and in elder individuals than in young individuals. ${ }^{7}$

In Japan, based on national surveys of cardiovascular diseases in 1980, 1990, and 2000, the estimated number of persons with AF rapidly increased..$^{8}$ After 2000 , a population-based study supported by the Japanese Circulation Society (JCS), of 630,138 participants aged $\geq 40$ years, ${ }^{9}$ found that the overall prevalence of AF in Japan was $0.86 \%$ (men, $1.35 \%$; women, $0.43 \%$ ) in 2003 . The prevalence of AF in men was consistently higher than that in women in all age groups. ${ }^{9}$ The age-specific prevalence of AF increased with age, especially at age $\geq 80$ years. ${ }^{9}$ In another community-based study in Japan of 41,436 adult 
residents aged $\geq 40$ years in Kurashiki City in 2006, the overall prevalence of AF was $1.6 \% .{ }^{10}$ In the present study, the increasing trend of the age-specific prevalence of $\mathrm{AF}$ was similar to that found in preceding studies.9,10 The latest overall prevalence of AF was $1.4 \%$ in the present study, which was higher than that in the JCS study, ${ }^{9}$ and slightly lower than that in the Kurashiki City study. ${ }^{\mathbf{1 0}}$ Given that the subject background and generations were different between the present study and the previous studies, it would be difficult to compare the prevalence directly between the studies. In the present study, the prevalence of AF increased from $0.8 \%$ to $1.4 \%$, especially in men from $1.7 \%$ to $2.9 \%$, between 2008 and 2015 . The reason for the increasing prevalence of AF from 2008 to 2015 may be explained by the increase in the frequency of comorbidities such as hypertension, diabetes, and metabolic syndrome (Table 1).

\section{Incidence of New-Onset AF}

The incidence of AF has been investigated in several epidemiological studies. In the Framingham study, the overall incidence of AF was $0.2 \%$ per year in men. ${ }^{11} \mathrm{AF}$ was identified in 26 men and in 16 women aged 70-79 years per 1,000 people during a follow-up period of 2 years; thus, the highest rate was in the $70 \mathrm{~s}$ age range. ${ }^{11}$ In the Cardiovascular Health Study, the incidence of AF increased with age, and the overall rate was 19.2/1,000 person-years. ${ }^{12}$ In the report of a community-based study from Olmsted County, Minnesota, the age- and sex-adjusted incidence rates of AF per 1,000 person-years were 3.04 in 1980 and 3.68 in $2000 .{ }^{13}$ The incidence of AF increased with age and generation, and was higher in older adults than that in younger adults, similar to that in the Framingham study ${ }^{14}$ and the Cardiovascular Health Study. ${ }^{\mathbf{1 2}}$

In Japan, similar to the reports from Western countries, ${ }^{11-14}$ the incidence of AF increased with age in both men and women. ${ }^{15-17}$ In an observational cohort study with 28,449 participants aged $\geq 20$ years (mean, 59.2 years) based on annual health checkups in Niigata, the incidence of AF per 1,000 person-years was 4.1 in men and 1.3 in women. ${ }^{15}$ In another community-based study with 30,010 participants aged $\geq 40$ years (median, 73 years) in Kurashiki, the incidence of AF per 1,000 person-years was 13.0 in men and 7.4 in women. ${ }^{16}$ The difference in the incidence of AF between these studies may be due to the difference in age of the populations. In a recent study in the Japanese general population aged 30-79 years, the Suita study, AF developed in 311 participants during the 95,180 personyears; thus, the incidence rate of AF was 3.3/1,000 personyears. ${ }^{17}$ In the present study, the incidence rate of AF was lower than that in the preceding cohort studies, ${ }^{15,17}$ even in subjects with a history of cardiac disease.

\section{Risk Factors for New-Onset AF in the General Population}

In the Framingham Heart Study, age, hypertension, diabetes mellitus, congestive heart failure, valvular disease, and myocardial infarction (only in men) were found to be significant risk factors for new-onset AF. ${ }^{14}$ In the Suita study in Japan, the risk factors for new-onset AF included age, systolic hypertension, overweight, excessive drinking, coronary artery disease, current smoking, arrhythmia other than AF, cardiac murmur, and non-HDL-C. ${ }^{17}$ These factors were scored from -5 to 9 points; consequently, the 10 -year probability of new-onset AF with scores $\leq 2,10-11$, or $\geq 16$ was $\leq 1 \%, 9 \%$, and $27 \%$, respectively. ${ }^{17}$ Age and hypertension were common risk factors in both studies. ${ }^{\mathbf{1 4 , 1 7}}$ In the present study, although many variables were associated with new-onset AF on univariate analysis, only age, male sex, and a history of cardiac disease were independent risk factors for new-onset AF on multivariate analysis. These results did not conflict with those in previous reports. ${ }^{14,17}$ Additional analysis was performed in the participants without a history of cardiac disease to determine the pure predictors for new-onset AF in the healthy general population without overt cardiac disease. Hypertension and BMI were identified as independent risk factors for new-onset AF in addition to age and male sex in the general population without overt cardiac disease. This also did not conflict with previous reports. ${ }^{14,17}$

Interventions are available for hypertension and BMI even in the general population via health-care promotion. ${ }^{18}$ Given that the cut-offs of SBP and BMI for new-onset AF were $129.5 \mathrm{mmHg}$ and $22.5 \mathrm{~kg} / \mathrm{m}^{2}$ in the present study, SBP $<130 \mathrm{mmHg}$ and standard body weight could be targets for the management of these risk factors to prevent new-onset $\mathrm{AF}$ in the healthy general population. In the Cardio-Sis study, in which non-diabetic patients with $\mathrm{SBP} \geq 150 \mathrm{mmHg}$ were randomly assigned to either target SBP groups $<140 \mathrm{mmHg}$ (usual control) or $<130 \mathrm{mmHg}$ (tight control), the incidence rate of new-onset $\mathrm{AF}$ in the tight control group was significantly lower than that in the usual control group (HR, 0.46; 95\% CI: 0.22-0.98). ${ }^{19}$ In contrast, in a population-based case-control study, the incidence rate of new-onset AF in participants with SBP $<120 \mathrm{mmHg}$ was significantly higher than that in those with SBP 120-129 mmHg (OR, 1.99; 95\% CI: 1.10-3.62), indicating a J-curve. ${ }^{20}$ In participants with $\mathrm{SBP} \geq 120 \mathrm{mmHg}$, however, SBP elevation of $14 \mathrm{mmHg}$ was associated with an increase in the risk of new-onset AF by $33 \%{ }^{20}$ Therefore, BP control must be important to prevent new-onset AF, but it remains controversial whether lower target $\mathrm{BP}$ is better. Obesity is also recognized as a risk factor for new-onset AF. ${ }^{21,22}$ In a cohort of the Framingham study, a 4\% increase in AF risk per 1-unit increase in BMI was observed in both men and women even after adjusting for several clinical confounding factors. ${ }^{21}$ In a recent report of the REVERSEAF study to evaluate the impact of body weight and risk factor management on the progression of AF, $\geq 10 \%$ weight loss resulted in $88 \%$ who reversed from persistent AF to paroxysmal or no AF. ${ }^{23}$ Body weight control would also be an important strategy to prevent new-onset AF.

\section{Study Limitations}

The present study had several limitations. First, participants of special health checkups were limited by age and insurance. People who have social insurance and/or are aged $<40$ or $\geq 75$ years at entry were not eligible for these special health checkups. Therefore, the overall prevalence and incidence of AF must be underestimated. Second, the diagnostic accuracy of the automatic ECG analysis was not validated. Given that electrocardiographs varied in model and vendor, diagnostic algorithms were not standardized. In addition, because the ECG recording was acquired only once per year at the time of annual health checkups, paroxysmal AF was not always detected. These issues could also be causes for underestimation of the prevalence and incidence of AF. Third, the cardiac disease histories obtained via the self-reported questionnaires during the special health checkups were not validated. These limitations may be similar to those in other cohort studies 
based on health checkups in the general population. In addition, the number of new-onset AF cases $(n=133)$ was small even for a 7-year follow-up period, and information of alcohol intake was lacking in the present study.

\section{Conclusions}

Prevalence of AF increased between 2008 and 2015. Age, male sex, hypertension, and BMI were significant predictors for future incidence of AF in the general population without overt cardiac disease. Given that interventions are available for hypertension and BMI, appropriate control of these factors may be important to prevent new-onset AF in the general population.

\section{Acknowledgments}

We would like to thank Mr. Junichi Murata for statistical analysis. This study was presented in part at the 66th Annual Scientific Session of the Japanese College of Cardiology (in Osaka, Japan, September 7, 2018).

\section{Funding}

The TAMA MED Project-AF is supported by the TAMA CITY Medical Association. This research was partially supported by the Takeda Research Support of Takeda Pharmaceutical Co., Ltd.

\section{Disclosures}

E.K. received remuneration from Ono Pharmaceutical and Bristol-Myers Squibb. The other authors declare no conflicts of interest.

\section{References}

1. Wolf PA, Abbott RD, Kannel WB. Atrial fibrillation as an independent risk factor for stroke: The Framingham Study. Stroke 1991; 22: 983-988.

2. Feinberg WM, Blackshear JL, Laupacis A, Kronmal R, Hart RG. Prevalence, age distribution, and gender of patients with atrial fibrillation: Analysis and implications. Arch Intern Med 1995; 155: 469-473.

3. Kodani E. Early detection of atrial fibrillation is the first step to prevent cardiogenic stroke: Usefulness of B-type natriuretic peptide. J Cardiol 2014; 65: 451-452.

4. Oda E, Watanabe K. Japanese criteria of metabolic syndrome. Circ J 2006; 70: 364

5. Majeed A, Moser K, Carroll K. Trends in the prevalence and management of atrial fibrillation in general practice in England and Wales, 1994-1998: Analysis of data from the general practice research database. Heart 2001; 86: 284-288.

6. Go AS, Hylek EM, Phillips KA, Chang Y, Henault LE, Selby JV, et al. Prevalence of diagnosed atrial fibrillation in adults: National implications for rhythm management and stroke prevention: The AnTicoagulation and Risk Factors in Atrial Fibrillation (ATRIA) Study. JAMA 2001; 285: 2370-2375.

7. Chugh SS, Havmoeller R, Narayanan K, Singh D, Rienstra M, Benjamin EJ, et al. Worldwide epidemiology of atrial fibrillation: A Global Burden of Disease 2010 Study. Circulation 2014; 129: $837-847$.

8. Ohsawa M, Okayama A, Sakata K, Kato K, Itai K, Onoda T, et al. Rapid increase in estimated number of persons with atrial fibrillation in Japan: An analysis from national surveys on cardiovascular diseases in 1980, 1990 and 2000. J Epidemiol 2005; 15: $194-196$.

9. Inoue H, Fujiki A, Origasa H, Ogawa S, Okumura K, Kubota I, et al. Prevalence of atrial fibrillation in the general population of Japan: An analysis based on periodic health examination. Int $J$ Cardiol 2009; 137: 102-107.

10. Iguchi Y, Kimura K, Aoki J, Kobayashi K, Terasawa Y, Sakai $\mathrm{K}$, et al. Prevalence of atrial fibrillation in community-dwelling Japanese aged 40 years or older in Japan: Analysis of 41,436 non-employee residents in Kurashiki City. Circ J 2008; 72: 909913.

11. Kannel WB, Abbott RD, Savage DD, McNamara PM. Coronary heart disease and atrial fibrillation: The Framingham Study. Am Heart J 1983; 106: 389-396.

12. Psaty BM, Manolio TA, Kuller LH, Kronmal RA, Cushman M, Fried LP, et al. Incidence of and risk factors for atrial fibrillation in older adults. Circulation 1997; 96: 2455-2461.

13. Miyasaka Y, Barnes ME, Gersh BJ, Cha SS, Bailey KR, Abhayaratna WP, et al. Secular trends in incidence of atrial fibrillation in Olmsted County, Minnesota, 1980 to 2000, and implications on the projections for future prevalence. Circulation 2006; 114: 119-125.

14. Benjamin EJ, Levy D, Vaziri SM, D'Agostino RB, Belanger AJ, Wolf PA. Independent risk factors for atrial fibrillation in a population-based cohort. The Framingham Heart Study. JAMA 1994; 271: 840-844.

15. Watanabe H, Tanabe N, Watanabe T, Darbar D, Roden DM, Sasaki S, et al. Metabolic syndrome and risk of development of atrial fibrillation: The Niigata preventive medicine study. Circulation 2008; 117: 1255-1260.

16. Iguchi Y, Kimura K, Shibazaki K, Aoki J, Kobayashi K, Sakai $\mathrm{K}$, et al. Annual incidence of atrial fibrillation and related factors in adults. Am J Cardiol 2010; 106: 1129-1133.

17. Kokubo Y, Watanabe M, Higashiyama A, Nakao YM, Kusano K, Miyamoto Y. Development of a basic risk score for incident atrial fibrillation in a Japanese general population: The Suita Study. Circ J 2017; 81: 1580-1588.

18. Du X, Dong J, Ma C. Is atrial fibrillation a preventable disease? J Am Coll Cardiol 2017; 69: 1968-1982.

19. Verdecchia P, Staessen JA, Angeli F, de Simone G, Achilli A, Ganau A, et al. Usual versus tight control of systolic blood pressure in non-diabetic patients with hypertension (Cardio-Sis): An open-label randomised trial. Lancet 2009; 374: 525-533.

20. Thomas MC, Dublin S, Kaplan RC, Glazer NL, Lumley T, Longstreth WT Jr, et al. Blood pressure control and risk of incident atrial fibrillation. Am J Hypertens 2008; 21: 1111-1116.

21. Wang TJ, Parise H, Levy D, D'Agostino RB Sr, Wolf PA, Vasan RS, et al. Obesity and the risk of new-onset atrial fibrillation. JAMA 2004; 292: 2471-2477.

22. Dublin S, French B, Glazer NL, Wiggins KL, Lumley T, Psaty $\mathrm{BM}$, et al. Risk of new-onset atrial fibrillation in relation to body mass index. Arch Intern Med 2006; 166: 2322-2328.

23. Middeldorp ME, Pathak RK, Meredith M, Mehta AB, Elliott $\mathrm{AD}$, Mahajan R, et al. PREVEntion and regReSsive Effect of weight-loss and risk factor modification on Atrial Fibrillation: The REVERSE-AF study. Europace 2018; 20: 1929-1935.

\section{Supplementary Files}

Please find supplementary file(s); http://dx.doi.org/10.1253/circj.CJ-18-1038 